\title{
Unusual inheritance of Becker type muscular dystrophy
}

\author{
LYDiA AgUILAR, RUBEN LISKER, AND GUILLERMO GARCIA RAMOS \\ From the Department of Genetics, Instituto Nacional de la Nutrición, San Fernando y Viaducto Tlalpan, \\ México 22, D.F.; and Department of Neurology, Instituto Nacional de la Nutrición, Mexico
}

SUMMARY A family with Becker type muscular dystrophy is described, in which two females were severely affected, giving the family tree the appearance of dominant inheritance.

Becker muscular dystrophy is clinically similar to the Duchenne type (Zundel and Tyler, 1965) but characterised by a later age of onset, slower progression, and in general by a much milder type of muscular dystrophy. Inheritance in both types is $\mathrm{X}$-linked recessive and though many heterozygous females of the Duchenne type have been reported as variably affected (Moser and Emery, 1974), this is not so for carriers of the Becker variety. The present report describes a family in which two females have severe manifestations of the disease.

\section{Case report}

The propositus was a 31-year-old male lawyer. The first manifestations of the disease appeared at age 19, when he noticed progressive difficulties in walking and climbing stairs. A year later he had to hold the balustrade to perform the latter task, and complained of severe muscle weakness. From the age of 21 he had noticed that both thighs had become progressively thinner while the calves had become enlarged, and 6 years later he had to use a walking cane. At present he is not chair ridden and lives a fairly active life, in spite of his physical handicap.
The physical examination showed waddling gate, moderate lumbar lordosis with winging of the scapulae, mild atrophy of the biceps and triceps muscles, severe atrophy of both quadriceps, and pro-o nounced pseudohypertrophy of the calves. Deep. tendon reflexes were diminished and the Gower's sign 1 was positive. Results of laboratory studies of the propositus and other affected members are shown in the Table.

\section{Family studies}

The pedigree is shown in the Fig. III.12 is now $23 \stackrel{2}{\Rightarrow}$ years old and from the age of 15 has had muscularo weakness. At present the muscles most affected are the shoulder girdle, biceps, gluteal, and quadricepsPseudohypertrophy of the calves is present and Gower's sign is negative.

The younger brother (III.13), 17 years old, was not:aware of muscle weakness; however, physical 3 . examination disclosed atrophy of the following muscles: deltoid, biceps, dorsal, supra and infra spinal, 3 rhomboid, and laevator scapulae. Mild atrophy of theo quadriceps was present and the calves were still? normal.

Table Results of laboratory studies performed in propositus and other affected members

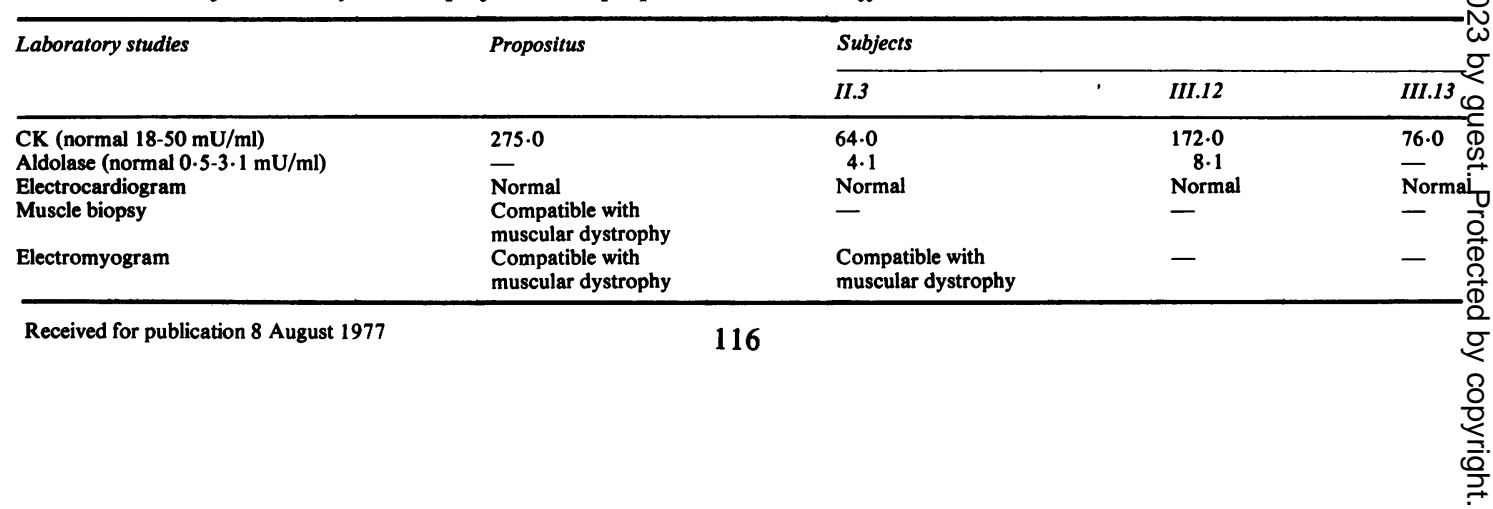




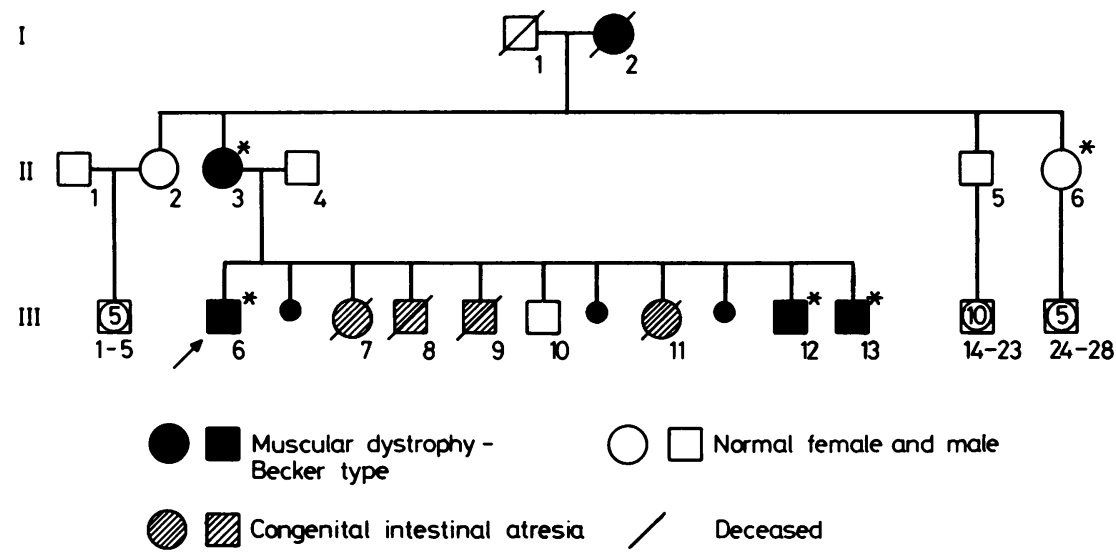

Propositus $\quad$ * Physical examination pertormed by us
Fig. Family tree.

The mother of the propositus (II.3) was 54 years old, and since the age of 30 she had had progressive difficulty in walking and climbing stairs, which at the time of examination she could do only if she took hold of the balustrade. Examination disclosed atrophy of the deltoid, biceps, and quadriceps muscles, with pseudohypertrophy of the calves.

II.3 told us that her mother (I.2) was affected in the same manner as she was, and that she had died at age 55 of a cerebrovascular accident. At that time she had the same walking and climbing difficulties as herself.

The only other member of the family available for examination was II.6, who was clinically normal and her CK and aldolase levels were normal as well. Her children (III.1 to 5) were also said to be normal, as was the rest of the family. An interesting finding was that several sibs of the propositus (III.7, 8, 9, and 11) died a few days after birth with an identical clinical picture. Congenital intestinal atresia was found during surgery in 2 of them.

\section{Discussion}

The clinical picture of the propositus seems typical of Becker muscular dystrophy (Emery and Skinner, 1976). The age of onset was late, the disease progressed slowly, the distribution of muscle weakness and wasting was proximal, deep tendon reflexes were diminished, there were no muscle contractures, and clear pseudohypertrophy of the calves was present. Serum CK and aldolase were abnormal, and the electromyographic studies and muscle biopsy were compatible with this diagnosis.

The two affected brothers, who were in the initial stage of the disease, already had similar abnormalities to the propositus, including abnormal serum CK (Table).

Differential diagnosis with other known forms of muscular dystrophy is relatively easy. The Duchenne type (Zundel and Tyler, 1965) has an earlier onset, progresses rapidly, and by the age of 31 most patients have died or have been chair ridden for years. The Emery-Dreifuss type (Emery and Dreifuss, 1966) is of late onset and slow progression but is characterised by absence of pseudohypertrophy of the calves, there are early muscular contractures, and cardiac involvement. The present cases had pseudohypertrophy of the calves, lacked muscular contractures, and the electrocardiogram was normal. The age of onset of the Mabry type (Mabry et al., 1965), though later than that of the Duchenne variety, is between 11 and 13 years, which is earlier than the present cases, and cardiac involvement is a constant feature.

Of the dominant forms of muscular dystrophy, the Landouzy-Dejerine type (Zundel and Tyler, 1965) can be differentiated because of the distribution of affected muscles in this disease, which do not usually affect the lower limbs, and the serum CK values are normal. The limb girdle variety and the so-called benign Duchenne type (Zundel and Tyler, 1965) are inherited in an autosomal recessive manner, which is unlikely in our cases. In addition, pseudohypertrophy of the calves is rare in limb girdle dystrophy and heterozygotes do not have increased serum CK values.

The unusual feature of the present family is the finding of a fairly severely affected female, the mother of the propositus. This must be rare: in the experience of A. E. H. Emery (1977, personal communication), carriers of Becker muscular dystrophy may have weakness but it is never gross and appears to be less 
severe than in the carriers of the Duchenne muscular dystrophy. As already mentioned, our patient is clearly more severely affected than this. A possible explanation in our case is of course Lyonisation, assuming that by chance the normal $\mathrm{X}$ chromosome was inactivated in more cells than in the usual non-manifesting heterozygote. The same assumption would have to be made to explain why the grandmother of the propositus was as affected as patient II.3.

The presence of congenital intestinal atresia in 4 sibs of the propositus is probably a coincidental finding and will not be discussed further.

\section{References}

Emery, A. E. H., and Dreifuss, J. N. (1966). Unusual type of benign X-linked muscular dystrophy. Journal of Neurology, Neurosurgery and Psychiatry, 29, 338-342.
Emery, A. E. H., and Skinner, R. (1976). Clinical studies in benign (Becker type) X-linked muscular dystrophy. Clinical Genetics $\mathbb{D}$ 10, 189-201.

Mabry, C. C., Roeckel, I. E., Munich, R. L., and Robertson, D. (1965). X-linked pseudohypertrophic muscular dystrophy with late onset and slow progression. New England Journal of? Medicine, 273, 1062-1070.

Moser, H., and Emery, A. E. H. (1974). The manifesting carrier in Duchenne muscular dystrophy. Clinical Genetics, 5, 271-284.

Zundel, W. S., and Tyler, F. H. (1965). The muscular dystrophies New England Journal of Medicine, 273, 573-543 and 273, 596-ه 601 .

Requests for reprints to Dr Rubén Lisker, Departmene of Genetics, Instituto Nacional de la Nutrición, Av San Fernando y Viaducto Tlalpan, Mexico 22, DF. 